\title{
Curcumin improves expression of SCF/c-kit through attenuating oxidative stress and NF-KB activation in gastric tissues of diabetic gastroparesis rats
}

\author{
Qi-Hui Jin ${ }^{1}$, Hong-Xia Shen², Hui Wang ${ }^{3}$, Qi-Yang Shou ${ }^{4}$ and Qiang Liu*
}

\begin{abstract}
Background: Diabetes mellitus is associated with many kinds of complications. Recent studies have shown that oxidative stress and inflammatory reactions have critical roles in the pathogenesis of diabetic gastroparesis. Curcumin is known to have antioxidant and anti-inflammatory properties. In the present study, we investigated the effect of curcumin on diabetic gastric motility in a Sprague Dawley rat model of type 1 diabetes mellitus.

Methods: Male SD rats were divided into a control group, a control group receiving curcumin, a diabetic group, and a diabetic group receiving curcumin. Diabetes was induced by intraperitoneal injection of streptozotocin. Curcumin $(150 \mathrm{mg} / \mathrm{kg})$ was given intragastrically for 6 weeks, and blood glucose levels and body weights were measured. Stomachs were excised for analysis of gastric emptying rates, and levels of oxidative stress. NF-kB, l-kB, and stem cell factor (SCF)/c-kit protein levels were assessed by western blot analysis, while the apoptosis of interstitial cells of Cajal (ICCS) was assessed by TUNEL staining.

Results: Curcumin-treated diabetic rats showed significantly improved gastric emptying rates [(59.4 \pm 7.5$) \%]$ compared with diabetic rats [(44.3 \pm 5.7$) \%]$, as well as decreased levels of MDA [21.4 $\pm 1.8(\mathrm{nmol} / \mathrm{mg})$ vs $27.9 \pm 2.1$ (nmol/mg)], and increased SOD activity [126.2 \pm 8.8 (units/mg) vs $107.9 \pm 7.5$ (units/mg)]. On the other hand, the gastric emptying level in the control group was not significantly different from that in the control group receiving curcumin treatment. In addition, curcumin-treated diabetic rats showed significantly increased levels of SCF/c-kit protein in stomach tissues, inhibited I-KB degradation and NF-KB activation, and reduced ICC apoptosis index $[(26.2 \pm 4.1) \%$ vs $(47.5 \pm 6.2) \%]$, compared with the diabetic group.
\end{abstract}

Conclusion: Curcumin treatment improved gastric emptying by blocking the production of oxidative stress, abolishing NF-kB signal transduction and enhancing expression of SCF/C-kit in rats with diabetic gastroparesis.

Keywords: Curcumin, Diabetic gastroparesis, Oxidative stress, NF-kB, Stem cell factor/c-kit, Interstitial cells of Cajal

\section{Introduction}

Diabetic gastroparesis is a disease of the digestive tract, defined as delayed emptying of a solid meal, and is seen in $30-50 \%$ of patients with type 1 or type 2 diabetes mellitus [1]. Patients often present upper gastrointestinal symptoms, such as early satiety, weight loss, abdominal bloating, abdominal discomfort, nausea, vomiting occur

\footnotetext{
* Correspondence: liuqianghare@163.com

'Department of Geriatric Medicine, The Second affiliated Hospital of Zhejiang University School of Medicine, Hangzhou, Zhejiang, China

Full list of author information is available at the end of the article
}

frequently, and impaired glycemic control, and the disease seriously affects patients' quality of life.

Gastroparesis is increasingly being recognized as a significant health problem. Although gastroparesis affects many diabetics worldwide, not only are the treatment options very limited, but also the treatments that are available for diabetic gastropathy are frequently ineffective. These include medical therapy, gastric electrical stimulation, surgical therapy, and nutritional support. Medications for gastroparesis include metoclopramide, domperidone, cisapride, and erythromycin. While these 
agents have been used for treating gastroparesis, they have been reported to be of only limited efficacy, and many patients cannot tolerate them because of their side effects. In diabetic patients with refractory gastroparesis, high-frequency gastric electrical stimulation by a permanently implanted system significantly improved upper digestive tract symptoms and represents an alternative surgical therapy for patients. Surgical procedures, such as gastrectomy and antrectomy are the last option for treatment, being controversial and in need of more study [2]. In patients with severe gastroparesis but normal small intestinal motility, jejunostomy tube feeding may be applied. While this provides nutritional support, it does not cure gastroparesis [3]. Diabetic gastroparesis is generally best treated medically, and only patients with severe diabetic gastroparesis who have failed to respond to medical therapy should undergo other therapies. Thus, finding drugs that show efficacy in treating diabetic gastroparesis is necessary.

Diabetic gastroparesis is associated with a loss of interstitial cells of Cajal (ICCs) in both humans and model animals [4]. ICCs can be identified in tissue by labeling with antisera to the receptor tyrosine kinase kit, a protein expressed on ICCs. Kit and its ligand stem cell factor (SCF) are also important survival factors for ICCs [5]. The increased oxidative stress associated with diabetes can lead to loss of or damage to ICCs in mice, while oxidative stress leads to damage and loss of ICC networks and the development of delayed gastric emptying [6]. Diabetes results in increased oxidative stress and has an important role in the pathogenesis of diabetic complications [7]. Overproduction of reactive oxygen species (ROS) results in oxidative damage, including lipid peroxidation, protein oxidation, and DNA damage, which can lead to cell death. Furthermore, ROS are known to act as second messengers to activate transcription factors such as nuclear factor kappa B (NF-kB). ROS generated during stress in gastric tissue may trigger the activation of the NF- $\mathrm{KB}$ signaling cascade; indeed, gastric emptying in diabetic rats is associated with activation of NF- $\mathrm{kB}-$ mediated inflammation.

Curcumin (1,7-bis-(4-hydroxy-3-methoxyphenyl)-1, 6heptadiene-3,5-dione) is the main active component of turmeric isolated from the plant curcuma longa $\mathrm{L}$. Curcumin is a multifunctional molecule with significant regulatory effects on cancer [8], inflammation [9] and diabetic-related diseases such as diabetic retinopathy [10], diabetic nephropathy [11], and diabetes cognitive dysfunction [12]. Curcumin is a potent scavenger of reactive oxygen and nitrogen species such as hydroxyl radicals and nitrogen dioxide radicals [13]. Several studies have demonstrated that curcumin inhibits activation of NF- $\mathrm{kB}$ proinflammatory signaling pathways [14]. Meanwhile, NF-kB transcription factors regulate a number of important physiological processes, including inflammation and immune responses, cell growth and survival, so inhibition of NF- $\mathrm{kB}$ signaling represents a viable strategy for disease therapy [15]. However, there has been very little research on the potential for curcumin to treat diabetic gastroparesis, or on its pharmacological mechanism.

The goal of this study was to determine whether, in a Sprague Dawley (SD) rat model of type 1 diabetes mellitus, middle-dose [16] curcumin could protect ICCs in diabetic rats with delayed gastric emptying by reducing oxidative stress and inhibiting NF- $\mathrm{KB}$ activation, increasing SCF/Kit expression, and normalizing the delay in gastric emptying.

\section{Materials and methods}

\section{Experimental rats and induction of diabetes}

Male SD rats (8 weeks of age) were bred in the Center of Experimental Animals, Zhejiang Chinese Medical University, (Hangzhou, China), where a specific pathogenfree (SPF)-level laboratory has been authorized by the Zhejiang provincial government. All rats were housed under conditions of controlled humidity (50-60\%). They were maintained under controlled light $(12 \mathrm{~h}$ day/night cycle) with free access to water and rodent chow. All animal experiments were performed in consistency with the license from the Zhejiang Province Science and Technology Office (Hangzhou, China) and with approval from the animal ethics committee of Zhejiang Chinese Medical University. All experiments conformed to guidelines for ethical conduct in the care and use of animals. Every effort was made to minimize stress to the animals.

Rats fasted for $12 \mathrm{~h}$ were subjected to a single intraperitoneal injection of streptozotocin (STZ), $50 \mathrm{mg} /$ $\mathrm{kg}$, freshly dissolved in $100 \mathrm{mM}$ sodium citrate buffer at $\mathrm{pH}$ 4.5. Age-matched normal rats received citrate buffer only. Development of diabetes was confirmed by fasting blood glucose (FBG) levels using a reagent kit (Roche, Shanghai, China). Rats with FBG levels higher than $11.1 \mathrm{mM}(200 \mathrm{mg} / \mathrm{dl})$ at $72 \mathrm{~h}$ after STZ injection were considered to be diabetic rats. Once the rats became diabetic, their glucose levels were measured daily. Experiments commenced 8 weeks after the development of diabetes to allow gastroparesis to develop.

\section{Experimental design}

Eight weeks after the development of diabetes, animals were divided into four groups, i.e. normal control male rats (Group I), diabetic male rats (Group II), curcuminsupplemented diabetic male rats (Group III), and curcumin-supplemented control male rats (Group IV). Rats in groups III and IV ( $\mathrm{n}=10$ each) were treated daily with curcumin $(150 \mathrm{mg} / \mathrm{kg}$; i.g.) for 6 weeks. Curcumin (purity > 95\%) from Fusong County Natural 
Biotechnology Company Ltd. (Jilin, China), was suspended in $0.5 \% \mathrm{w} / \mathrm{v}$ sodium carboxymethyl-cellulose (CMC-Na) solution. Rats in groups I and II ( $\mathrm{n}=10$ each) received $0.5 \%$ CMC-Na solution only. After treatment for 6 weeks, the animals were sacrificed under ethyl ether anesthesia, blood was collected by femoral vein bleeding and serum was separated. Stomachs were rapidly removed, and tissue samples collected from animals were stored at $-80^{\circ} \mathrm{C}$ until processed for biochemical assays. Gastric emptying, oxidative stress, NF$\kappa \mathrm{B}$ activation, ICCs and SCF/Kit expression in stomachs were also studied at the end of the sixth week of treatment ( $14^{\text {th }}$ week of diabetes).

\section{Gastric emptying studies}

The standard method for preparing a phenol red marker meal was employed as described previously [17]. Gastric emptying was determined using a modification of a previously reported procedure [18]. Rats were allowed free access to water until $3 \mathrm{~h}$ before gavage administration of curcumin. A solution of $0.1 \%(\mathrm{w} / \mathrm{v})$ phenol red in aqueous sodium carboxymethylcellulose $(1.5 \% \mathrm{w} / \mathrm{v})$ was used as a test meal. Curcumin was given $1 \mathrm{~h}$ before the oral administration of the test meal. Twenty minutes after the administration of the test meal, the rats were sacrificed. The stomachs were then exposed by laparotomy and removed. Rats treated with the vehicle (saline, $0.9 \%$ sodium chloride solution, $0.2 \mathrm{~mL}$ ) were sacrificed immediately after oral administration of the test meal and the phenol red content in the stomach was considered as the standard (100\%). The removed stomachs were incised in $40 \mathrm{~mL}$ of $\mathrm{NaOH}$ solution $(0.1 \mathrm{~N})$ and the contents were dissolved. A 1-mL aliquot of the washing solutions was added to $2 \mathrm{~mL}$ of trichloroacetic acid $(7.5 \% \mathrm{w} / \mathrm{v})$ to precipitate proteins. After centrifugation $(2500 \times g)$ for $20 \mathrm{~min}, 1 \mathrm{ml}$ of the supernatant was added to $1 \mathrm{ml}$ of $\mathrm{NaOH}(1 \mathrm{~N})$ to develop the maximum intensity of color. The absorbance at $558 \mathrm{~nm}$ of the solution was then measured using a spectrophotometer (U-1080; Hitachi Ltd., Tokyo, Japan). Gastric emptying was calculated according to the following formula:

$$
\text { Gastric emptying }(\%)=(1-\mathbf{X} / \mathbf{Y}) \times 100 \text {, }
$$

where $\mathbf{X}$ is the absorbance of phenol red remaining in the stomach 20 min after phenol red administration and $\mathbf{Y}$ is the mean absorbance of phenol red recovered from the stomachs of control mice immediately after phenol red administration.

\section{Determination of MDA and SOD levels in smooth muscle of gastric antrum}

The stomachs were excised, weighed, and immediately frozen at $-70^{\circ} \mathrm{C}$. Frozen tissue from each rat was homogenized in ice-cold phosphate buffer (KCl $140 \mathrm{mM}$, phosphate $20 \mathrm{mM}, \mathrm{pH} 7.4$ ) and centrifuged at $3000 \times g$ for $10 \mathrm{~min}$. The content of malonaldehyde (MDA), an index for lipid peroxidation, was determined using the thiobarbituric acid (TBA) method with slight modification [19]. Briefly, $100 \mu \mathrm{l}$ of tissue homogenate was mixed with $200 \mu \mathrm{l}$ of work solution containing $0.37 \%$ TBA. The mixture was incubated at $100^{\circ} \mathrm{C}$ for 15 min and subsequently cooled. To extract MDA, $375 \mu \mathrm{l}$ of N-butanol was added, followed by vortexing vigorously for $10 \mathrm{~s}$. After centrifugation, the upper N-butanol layer was transferred to a glass tube. The absorbance of the butanol phase was measured at $532 \mathrm{~nm}$. MDA content is expressed as $\mathrm{nmol} / \mathrm{mg}$ protein. For measurement of SOD activity, $20 \mu \mathrm{l}$ of tissue homogenate was mixed with $200 \mu$ l of reaction solution containing nitroblue tetrazolium chloride (NBT, $750 \mu \mathrm{M}$ ), and incubated for $20 \mathrm{~min}$ at $37^{\circ} \mathrm{C}$. The absorbance at $560 \mathrm{~nm}$ was measured. Enzyme activity is expressed as units/g protein and 1 unit of enzyme was defined as the amount of enzyme required to inhibit the reduction of NBT by $50 \%$.

\section{Semiquantitative RT-PCR measurement of SCF and c-kit}

The proximal stomach (40-50 mg) was harvested, and the mucosa was removed by dissection. The tissue was mechanically homogenized under RNase-free conditions and dissociated with Tripure isolation reagent (Roche, Switzerland) on ice for 5 minutes, and total RNA was extracted according to the manufacturer's instructions. Total RNA was quantified spectrophotometrically at 260 and $280 \mathrm{~nm}$, with the A260/A280 ratio ranging from 1.8 to 2.0. RNA integrity was verified by agarose gel electrophoresis, followed by ethidium bromide staining, and RNA was used for immediate reverse transcription or stored at $-80^{\circ} \mathrm{C}$ in RNase-free water. Two-step reverse transcriptase-polymerase chain reaction (RT-PCR) was performed using the Revertra ace- $\alpha$ - first strand cDNA synthesis kit (Tiangen Biotech, Beijing, China) and $2 \times$ Taq PCR master mix (Tiangen Biotech), according to the manufacturer's instructions. A fixed amount of RNA $(0.5 \mu \mathrm{g})$ was reverse transcribed. Glyceraldehyde-3-phosphate dehydrogenase (GAPDH) was selected as an internal standard. All PCR primers were designed and synthesized by Biosune (Shanghai, China). The primer sequences and lengths of the PCR products are as follows: GAPDH, forward: 5'-GACAACTITG-GCATC GTGGA-3', reverse: 5'-ATGCAGGGATGATGT-TCTG G-3', 150 bp; SCF, forward: 5'-GGA CTT CAT GGT GGC ATC TG-3', reverse: 5'-GCC CTT GTA AGA CTT GAC TG-3', 285 bp; and c-kit, forward: 5'-GTG GTT AAA GGA AAC GCT CG-3', reverse: 5'-CAT ACA TTT CAG CAG GTG CG-3', 400 bp. Reaction conditions were optimized for each of the genes by varying the annealing temperature $\left(58^{\circ} \mathrm{C}\right.$ for $\mathrm{GAPDH}, 58^{\circ} \mathrm{C}$ 
for SCF, and $62^{\circ} \mathrm{C}$ for c-kit) and different numbers of PCR cycles [20]. The PCR products were separated on $2 \%$ agarose gels at $100 \mathrm{~V}$ for 30 minutes. Gel images were displayed on the liquid crystal display monitor of an ultraviolet transillumination PhotoDoc-Ite system equipped with a CCD camera (Bio-Rad Gel Doc 2000, Bio-Rad Laboratories, Hercules, CA) and preserved for intensity analysis. The relative mRNA levels of the selected genes were calculated as the ratio to GAPDH expression.

\section{Levels of SCF, C-Kit, ІкB and NF-KB assessed by western blot analysis}

About $50 \mathrm{mg}$ of tissue was taken from the near proximal stomach. Tissues were cut into little pieces of about $0.25 \mathrm{~cm}^{3}$, homogenized, and dissociated in radioimmunoprecipitation assay lysis buffer (Hushang Biotechnology, Shanghai, China), containing $50 \mathrm{mM}$ tris, $150 \mathrm{mM} \mathrm{NaCl}, 1 \% \mathrm{NP}-40,0.5 \%$ sodium deoxycholate, $1 \%$ sodium dodecyl sulfate, $1 \mathrm{mM}$ PMSF, sodium orthovanadate, sodium fluoride, ethylenediaminetetraacetic acid, and leupeptin at $4^{\circ} \mathrm{C}$ for 30 minutes. Homogenates were centrifuged at $12000 \times g$ for 5 minutes at $4^{\circ} \mathrm{C}$, and the supernatants were collected and used as total protein. Equal amounts of protein were electrophoresed by SDS-PAGE in $10 \%$ or $15 \%$ polyacrylamide gels. Proteins were transferred onto nitrocellulose membranes (Hushang Biotechnology) by semidry blotting. Membranes were blocked with Tris-buffered saline $0.1 \%$ Tween 20 (TBST) containing 5\% milk for 60 minutes at room temperature, and then immunoblotted with appropriately diluted primary antibodies at $4^{\circ} \mathrm{C}$ overnight. After washing three times with TBST, the blots were incubated with HRP-conjugated secondary antibody for 60 minutes at room temperature. Then, the complexes were visualized using an iChemi XR imaging system (WD9431A, Bomeike Biotechnology, China) with chemiluminescence reagents (Tigsun Biological Science Technology, Tianjin, China). Semi-quantification was performed using Quantity One software, version 4.6.2 (Bio-Rad). The following antibodies were used: anti-SCF, 1:200, c-kit, 1:200, anti-IкB and anti-NF-кB p65 and GAPDH, 1:500 (Hushang Biotechnology, Shanghai, China).

\section{Quantification of NF-KB -DNA binding by electrophoretic mobility shift assay}

Nuclear extracts were prepared from stomach lysates as described previously [21]. NF-kB activation was determined by an electrophoretic mobility shift assay (EMSA), and nuclear translocation of NF-kB was assessed as described previously (GS009, Beyotime Institute of Biotechnology, Shanghai, China) [22]. For NF-kB binding reactions, $5 \mu \mathrm{g}$ of nuclear protein extract was incubated at room temperature for $20 \mathrm{~min}$ with reaction buffer containing $20 \mathrm{mM}$ HEPES, pH 7.9, $50 \mathrm{mM} \mathrm{KCl}$, $0.1 \mathrm{mM}$ EDTA, $1 \mathrm{mM}$ DTT, 5\% glycerol, $200 \mu \mathrm{g} / \mathrm{mL}$ $\mathrm{BSA}$, and $2 \mu \mathrm{g}$ of poly (dI-dC). Then, ${ }^{32} \mathrm{P}$-labeled double-stranded oligonucleotide (1 ng $\geq 1 \times 105 \quad \mathrm{cpm}$ ) containing the NF- $\mathrm{kB}$ binding consensus sequence $\left(5^{\prime}\right.$ GGCAACCTGGGGACTCTCCCTTT-3') was added to the reaction mixture for an additional $10 \mathrm{~min}$ at room temperature. The reaction products were fractionated on a non-denaturing $6 \%$ polyacrylamide gel for $60 \mathrm{~min}$ at $350 \mathrm{~V}$, which was then dried and subjected to autoradiography at $-70^{\circ} \mathrm{C}$ overnight. For competition assays, excess oligonucleotide (100-fold molar excess) competitor was pre-incubated with nuclear extracts for $20 \mathrm{~min}$ at room temperature. A mutant NF- $\mathrm{kB}$ oligonucleotide $\left(5^{\prime}\right.$ GGCAACTGCTCACTCTCCСТTT-3') was used for the competition assay. Signals were densitometrically analyzed.

\section{Double immunofluorohistochemistry with terminal deoxynucleotidyl transferase-mediated dUTP-biotin nick end labeling assay (TUNEL) and c-kit staining}

Fluorescence immunohistochemistry for c-kit (using the antibody from Santa Cruz) and TUNEL staining were performed on $10-\mu \mathrm{m}$ sections using a modification of the procedure published by the manufacturer of the TUNEL kit (TACS sTdT, Trevigen Inc, Gaithersburg, MD). TUNEL-positive cells were labeled with fluorescein (Ex 488, Em 505-550), c-kit-positive cells were labeled with Cy3 (Ex 543, Em 560-615), and nuclei were labeled with DAPI (Ex 364, Em 385-470). Tissue specimens were embedded in fluorescence mounting medium and investigated by confocal laser scanning microscopy [23]. Approximately 200 cells were counted per field, five fields were examined per slide and five slides were examined per group. The percentages of TUNELand c-kit-positive apoptotic cells were denoted as the apoptotic index (AI) (\%).

\section{Statistical analysis}

All data are presented as means \pm SD. To compare data among groups of animals, one-way analysis of variance (one-way ANOVA) and Duncan comparisons were employed. All statistical tests were performed using SPSS for Windows, version 13.0 (SPSS Inc, Chicago, IL). Differences were considered statistically significant at $P<0.05$.

\section{Results}

Effect of curcumin on body weight and blood glucose of diabetic rats

Plasma glucose levels were highly elevated in diabetic rats (Group II) $[(322 \pm 41) \mathrm{mg} / \mathrm{dl}]$ compared with those in normal control rats (Group I) $[(98 \pm 12) \mathrm{mg} / \mathrm{dl}]$. There was a marked decline in the body weights of 
Group II rats [(298 \pm 16$)$ g] compared with age-matched Group I rats $[(449 \pm 21) \mathrm{g}]$. Chronic curcumin-treated diabetic rats (Group III) showed no significant improvements in body weight and no decline in plasma glucose levels compared with Group II rats [Group III, body weight $(324 \pm 19) \mathrm{g}$ and glucose $(302 \pm 38) \mathrm{mg} / \mathrm{dl}]$ (Table 1).

\section{Effect of curcumin on gastric emptying}

Gastric emptying was significantly delayed in SD rats that had had diabetes for 8 weeks. The amount of gastric emptying in Group II was $44.3 \pm 5.7 \%$, which was significantly lower than that in Group I [(76.2 \pm 4.3$) \%$, $P<0.01]$, and diabetic rats undergoing curcumin treatment [(Group III); $(59.4 \pm 7.5) \%, P<0.05]$. However, no significant difference was noted between Group I and Group IV rats [(73.3 $\pm 5.2 \%), P>0.05]$ (Figure 1 ).

\section{Curcumin treatment decreased MDA formation, increases SOD activity}

We investigated oxidative stress using several methods because glucose-induced oxidative stress has been postulated to be a key mechanism in chronic diabetic complications. Diabetic rats exhibited increased MDA levels [Group I $15.7 \pm 1.7(\mathrm{nmol} / \mathrm{mg})$ vs Group II $27.9 \pm$ $2.1(\mathrm{nmol} / \mathrm{mg}), P=0.006]$ and decreased SOD levels [Group I $146.2 \pm 9.3(\mathrm{u} / \mathrm{mg})$ vs Group II $107.9 \pm 7.5$ (u/mg), $P=0.008$ ], a molecular marker of oxidative stress (Figure 2). Six weeks of curcumin treatment reduced the degree of MDA upregulation [Group III, $21.4 \pm 1.8(\mathrm{nmol} / \mathrm{mg}), P=0.033$ versus Group $\mathrm{I}$ and $P=0.004$ versus Group II], and improved the SOD down-regulation [Group III $126.2 \pm 8.8$ (units/mg), $P=0.036$ versus Group I and $P=0.001$ versus Group II]. Curcumin significantly enhanced SOD activity and reduced MDA levels in stomach homogenates. Furthermore, no significant difference were noted between Group I and Group IV animals $(P>0.05$; Figure 2).

\section{Curcumin increases SCF and c-kit protein levels}

Representative images of the RT-PCR analysis of SCF in the stomach tissues of rats in each group are shown in Figure 3A. Compared with Group I, the SCF was significantly lower in Group II $[(0.44 \pm 0.02)$ vs $(0.69 \pm 0.03)$,

Table 1 Blood glucose level and body weight in four groups

\begin{tabular}{ccccc}
\hline Groups & Group I & Group II & Group III & Group IV \\
\hline Blood glucose(mg/dl) & $98 \pm 12$ & $322 \pm 41^{*}$ & $302 \pm 38^{* \#}$ & $100 \pm 11$ \\
Body weight(g) & $449 \pm 21$ & $298 \pm 16^{*}$ & $324 \pm 19^{*}$ & $476 \pm 27$
\end{tabular}

Group I=normal control rats; Group II=diabetic control rats; Group III= diabetic + curcumin treated rats $(150 \mathrm{mg} / \mathrm{kg})$; Group IV=normal + curcumin treated rats $(150 \mathrm{mg} / \mathrm{kg})$. Results are presented as mean $\pm \mathrm{SD}$. ${ }^{*} P<0.05$ (compared to Group I), " $P>0.05$ (compared to Group II).

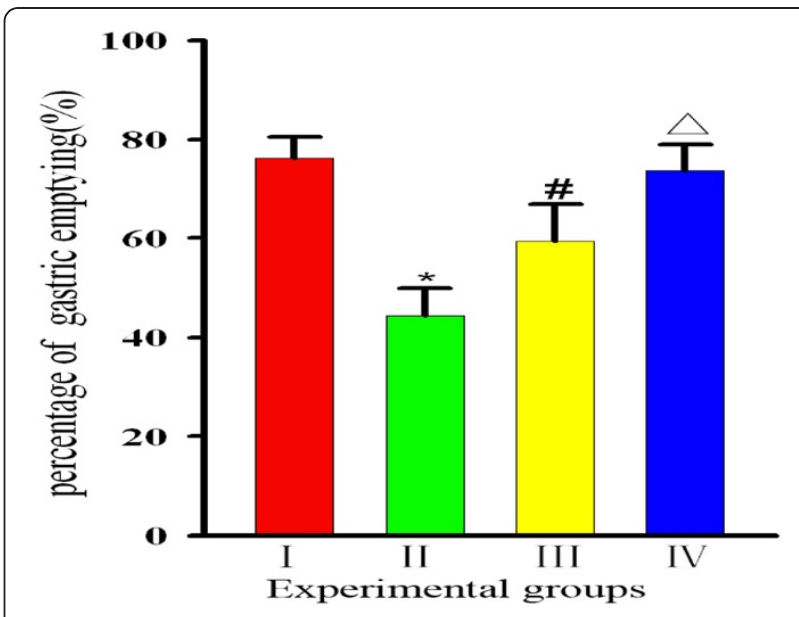

Figure 1 Effects of curcumin on gastric emptying in diabetic rats. Group I=normal control rats $(n=10)$; : Group $\|=$ diabetic control rats $(n=10) ;:$ Group $\|$ =diabetic + curcumin treated rats $(n=10) ;$ : Group IV=normal + curcumin treated rats $(n=10)$. All values are expressed as the mean $\pm S D$. ${ }^{*} p<0.01$ (compared to Group I), \# $p<0.05$ (compared to Group II), $\Delta p>0.05$ (compared to Group I).

$P=0$.002], and a comparison of the values in Group III revealed that the SCF level in curcumin-treated rats was greater than that in Group II $[(0.58 \pm 0.04)$ vs $(0.44 \pm$ 0.03) $P=0$.003]. However, no differences were noted between Groups I and IV $[(0.69 \pm 0.03)$ vs $(0.66 \pm 0.03)$ $P=0.56$ ] (Figure $3 \mathrm{~B}$ ). Western blot analysis (Figure 4A, $B$ ) revealed that the level of SCF in stomach tissues from Group II rats was significantly lower than those in Group I and III rats [ratios of $(0.33 \pm 0.02)$ vs $(0.47 \pm$ $0.03)$ and $(0.41 \pm 0.02)$, respectively, $P<0$.05)]. However, no significant difference was found between Group IV and Group I rats $[(0.45 \pm 0.03)$ vs $(0.47 \pm 0.03)$, $P>0.05)]$, suggesting that curcumin intervention could effectively restore local SCF protein levels in the stomach tissues of diabetic rats.

RT-PCR analysis showed that the expression levels for c-kit in stomach tissues were $0.78 \pm 0.04,0.37 \pm 0.02$, and $0.59 \pm 0.03$ for Groups I, II and III, respectively. The c-kit expression levels in Groups II and III rats were lower than that in Group I rats. However, a comparison of Groups II and III revealed that the c-kit level in curcumin-treated rats was greater than that in nontreated diabetic rats $(P<0.05$, Figure 3B). Similar outcomes were demonstrated by western blot analysis (Figure 4B). The levels of c-kit protein (ratios of $0.45 \pm$ $0.03,0.21 \pm 0.02$ and $0.34 \pm 0.02$, respectively, for Groups I, II and III) were much greater in Group III than in Group II $(P<0.05$, Figure 4B), and the level in Group III was lower than those in Groups I and IV. Both analyses indicated that 6 weeks of curcumin intervention could significantly restore the decrease in c-kit levels in diabetic rats. 

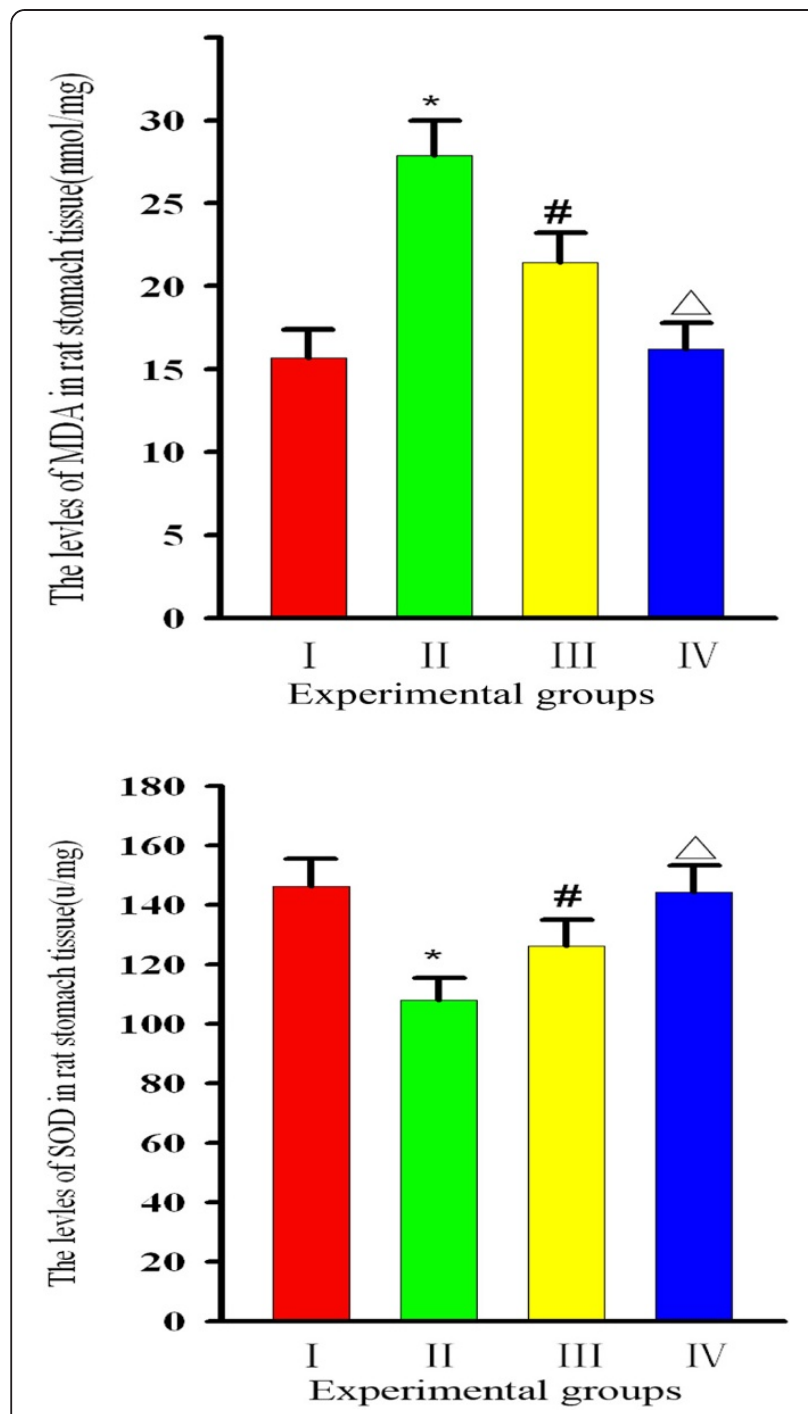

Figure 2 Effects of curcumin on MDA and SOD in diabetic rats. The levels of MDA was decreased after treated with curcumin, the levels of SOD was increased after treated with curcumin. : Group I=normal control rats $(n=10)$; : Group II=diabetic control rats $(n=10)$; Group III=diabetic + curcumin treated rats $(n=10)$; : Group IV= normal + curcumin treated rats $(n=10)$. All values are expressed as the mean \pm SD. ${ }^{*} p<0.01$ ( compared to Group I), \# $p<0.01$ (compared to Group II), $\Delta p>0.05$ (compared to Group I).

\section{Curcumin inhibits I-KB degradation and NF-KB activation}

Reports indicate that increased and chronic oxidative stress can activate or perturb NF-kB activity [24]. We investigated whether curcumin could result in activation of the NF- $\mathrm{kB}$ signaling pathway. To do this, we measured the levels of NF- $\mathrm{kB}$ in the presence or absence of curcumin to identify whether NF- $\mathrm{B}$ was activated. First, we evaluated the protein levels of $I-\kappa B$, to which inactivated NF- $k B$ binds. We found that the level of $I-\kappa B$ in Group I rats was higher than that in Group II rats, while the level in Group III rats was lower than that in Group II rats $(\mathrm{p}<0.01)$, but higher than the levels in
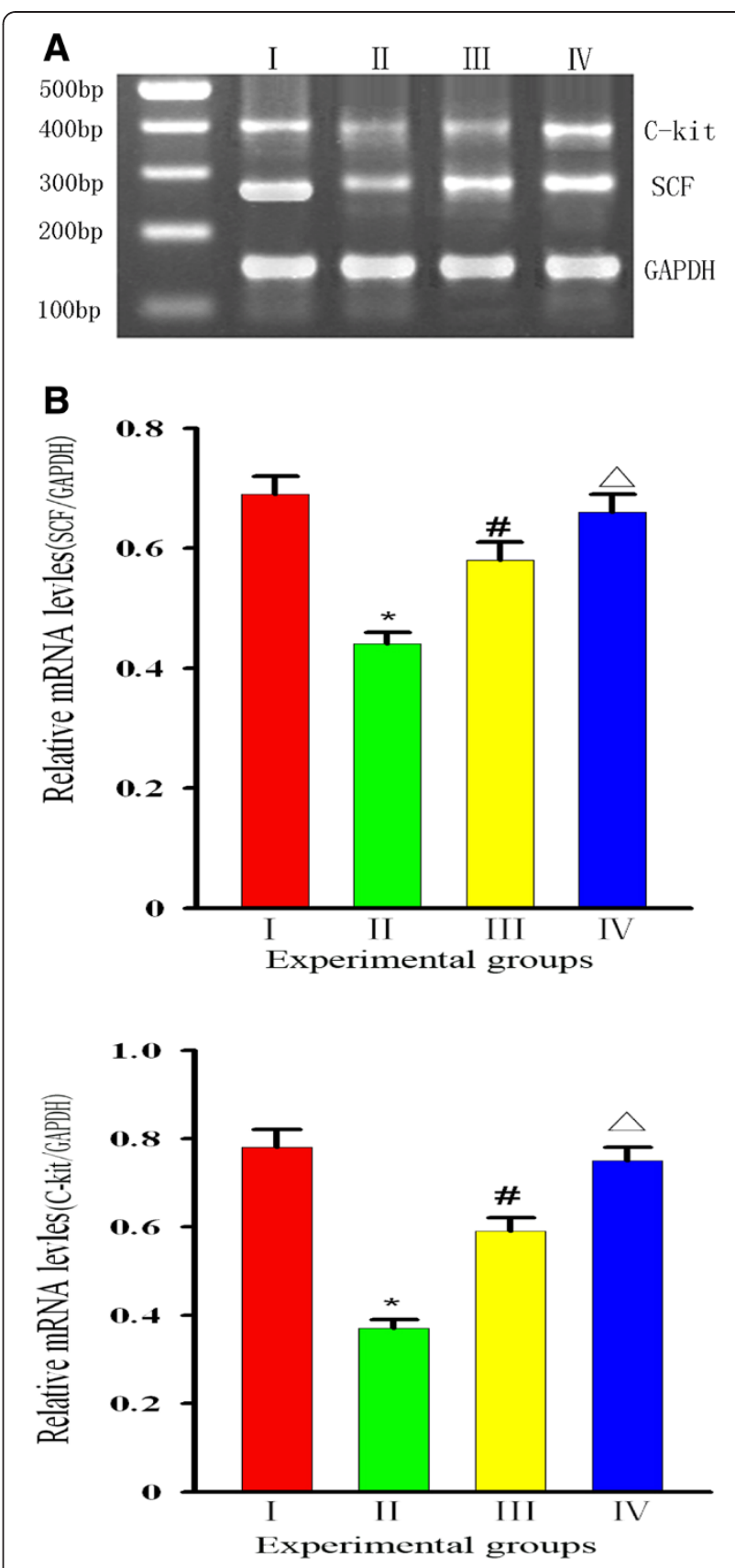

Figure 3 Changes in SCF/GAPDH and C-kit/GAPDH by RT-PCR analysis. (A) Representative images of gel electrophoresis of GAPDH,SCF, and c-kit in rats of each group. (B) Group levels of relative mRNA expression of SCF and c-kit, with products quantified by ratio to GAPDH. : Group I=normal control rats $(n=10)$; : Group $\|=$ diabetic control rats $(n=10) ;$ : Group III=diabetic + curcumin treated rats $(n=10) ;$ : Group IV=normal + curcumin treated rats $(n=10)$. All values are expressed as the mean $\pm S D .{ }^{*} p<0.01$ (compared to Group I.), \# $p<0.05$ (compared to Group II), $\Delta p>0.05$ (compared to Group I). 

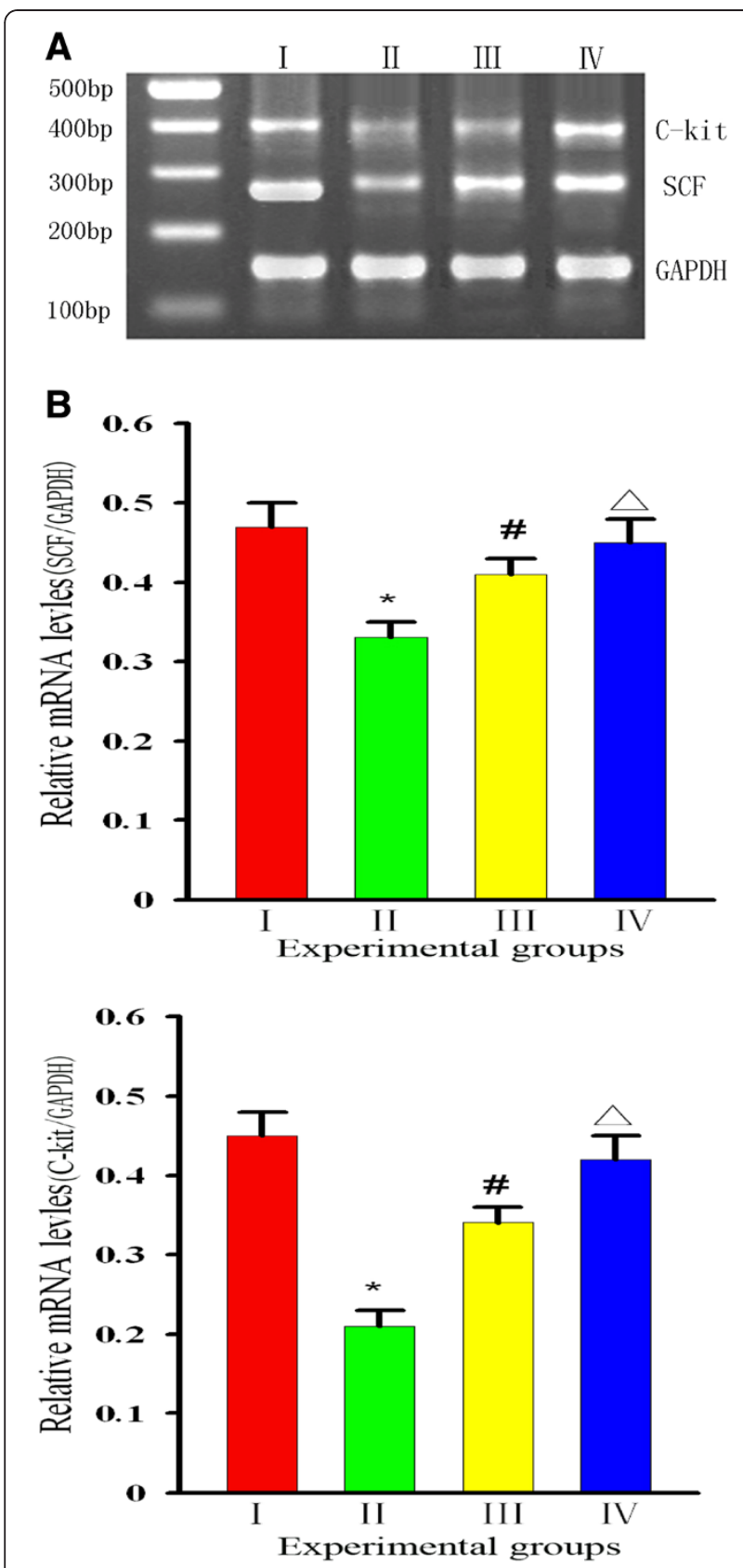

Figure 4 Changes in SCF/GAPDH and C-kit/GAPDH by Western blot analysis. (A) Representative protein band images of SCF, C-kit, and glyceraldehydes-3-phosphate dehydrogenase (GAPDH).

(B) Group levels of relative SCF and c-kit protein expressed by ratio to GAPDH,respectively. : Group I=normal control rats $(n=10)$; : Group $\|=$ diabetic control rats $(n=10) ;$ : Group III=diabetic + curcumin treated rats $(n=10)$; : Group IV=normal + curcumin treated rats $(n=10)$. All values are expressed as the mean $\pm S D$. ${ }^{*} p<0.01$ (compared to Group I), \# $p<0.01$ (compared to Group II), $\Delta p>0.05$ (compared to Group l).
Groups I and IV rats $(\mathrm{p}<0.05)$. Then, we examined whether curcumin could block NF-kB. We found that diabetes (Group II) led to an increase in NF- $\mathrm{BB}$ levels [Group I $75.5 \pm 7.7(\mathrm{pg} / \mathrm{ml})$ vs Group II $102.8 \pm 12.4$ $(\mathrm{pg} / \mathrm{ml}), P=0.001]$, while treatment with curcumin [Group III $91.3 \pm 8.9(\mathrm{pg} / \mathrm{ml})]$ prevented this effect. Based on this finding, we suggested that curcumin suppresses activation of NF- $\mathrm{kB}$ [Group IV $70.9 \pm 8.1$ (pg/ml), $P=0.026]$ (Figure 5). We examined whether curcumin could block NF-kB translocation into the nucleus, because nuclear translocation is recognized as a cell reaction to ROS stimulation and seems to correlate with NF-kB-mediated transcriptional activation. To assess this, we measured the level of NF- $\kappa B$ in the nucleus by EMSA. Development of diabetes induced an increase in NF- $\mathrm{BB}$ levels in the nucleus, while treatment with curcumin prevented this effect (Figure 6). Thus, we suggested that curcumin not only indirectly suppresses activation of NF-kB-DNA binding, but that it also suppresses activation upstream of I- $\mathrm{kB}$.

\section{Curcumin reduces apoptosis of ICCs and promotes their proliferation in stomach tissues}

To further analyze the chemopreventive action of curcumin on diabetic gastroparesis, we examined its effect on apoptosis in diabetic stomach sections by double immunofluorohistochemistry. Figure 7 shows representative images of apoptosis in stomach tissue sections from rats of all four groups. The chromogen-generated yellow stain is an indication of apoptotic ICCs. It should be noted that in almost every case the yellow stain overlaps the condensed chromatin of apoptotic bodies, thus confirming that the results of the double immunofluorohistochemistry assay correlate well with the morphological appearance of apoptosis. The rate of apoptosis was generally very low in Group I rats. Typically, in sections from diabetic rats, we found an average of 80-100 apoptotic cells in a field of about 200 cells. This number decreased to 40-50 stained cells in the curcumin-treated rats. As seen in Table 2, the proportion of apoptotic ICCs in the stomachs [AI:(47.5 \pm 6.2)\%] of Group II rats was markedly higher than that in the stomachs of Group I rats [AI: $(6.4 \pm 1.8) \%]$. This effect of diabetes was mostly reversed by curcumin $[(26.2 \pm 4.1) \%$ for Group III], with a difference that was statistically significant $(P<0.05)$. However, no significant difference in AI was noted between Group I and IV rats [AI for Group IV: $(7.1 \pm 2.4) \%](P>0.05)$.

\section{Discussion}

Numerous recent studies have demonstrated the ability of curcumin to halt or prevent certain types of cancer, decrease inflammation, and improve cardiovascular health. However, very few studies have examined its 


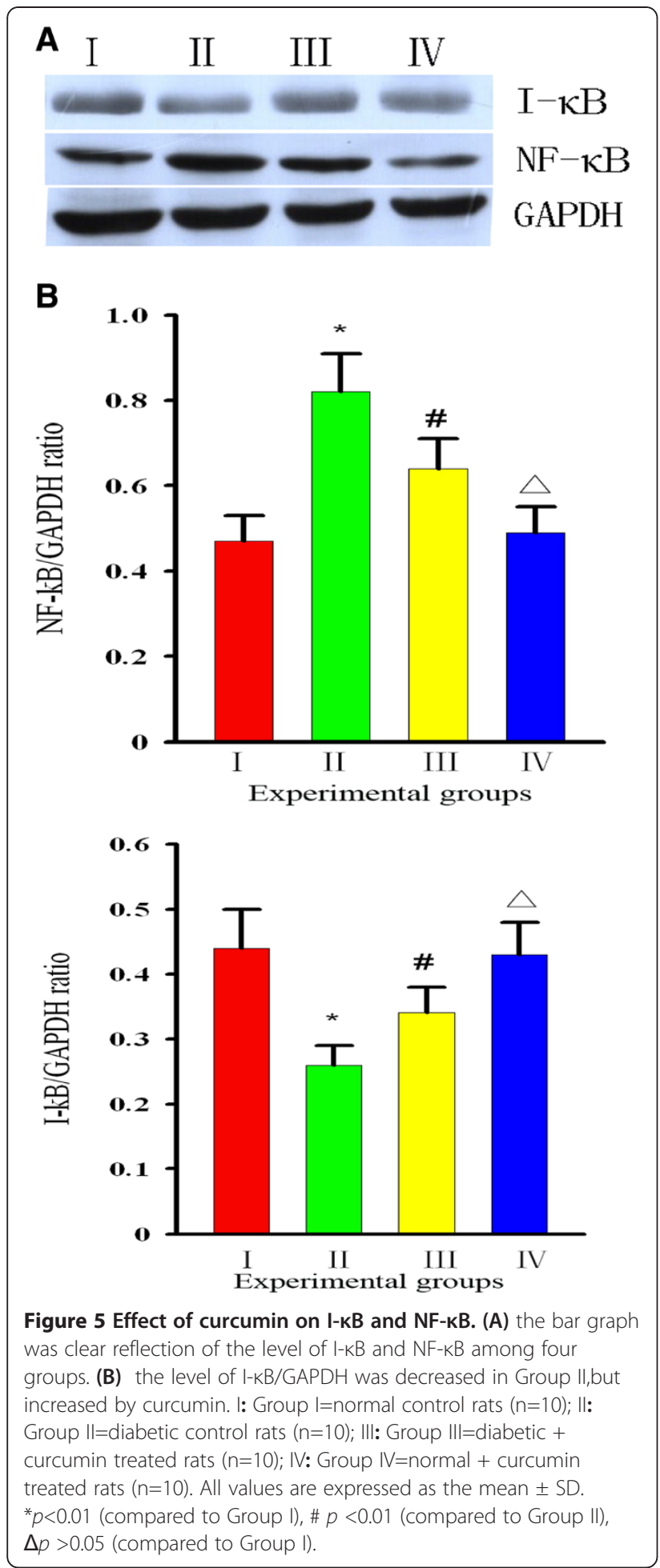

ability to protect against diabetic gastroparesis. In our study, we demonstrated that supplementation with curcumin attenuated oxidative stress and NF- $\mathrm{kB}$ activation, and prevented the down-regulation of SCF/c-kit protein level in diabetic rats. Our result suggests that

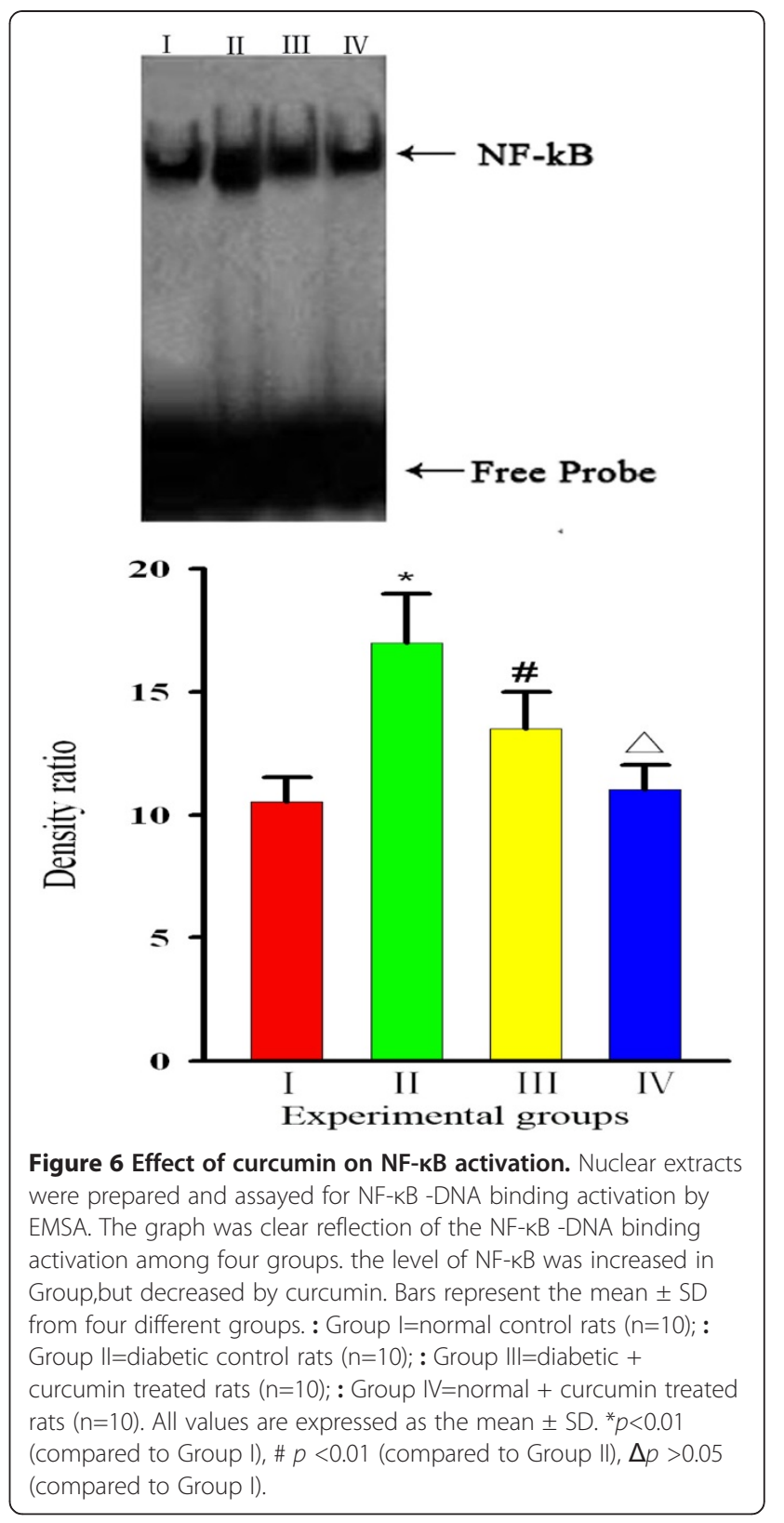

the increased gastric dysfunction in diabetic rats can be prevented by curcumin treatment.

Data presented in this study show that SCF/c-kit is down-regulated after the development of diabetes and the concurrent increase in the level of oxidative stress. This down-regulation of SCF/c-kit was lost in all rats that went on to develop delayed gastric emptying and maintained in all rats that did not develop delayed gastric emptying. Failure to maintain down-regulation of $\mathrm{SCF} / \mathrm{c}-\mathrm{kit}$ and develop delayed gastric emptying was associated in all rats with high levels of markers of oxidative stress and NF-kB. In the curcumin-treated rats, ICCs were protected, suggesting that the maintenance of normal gastric function requires decreased ROS, 


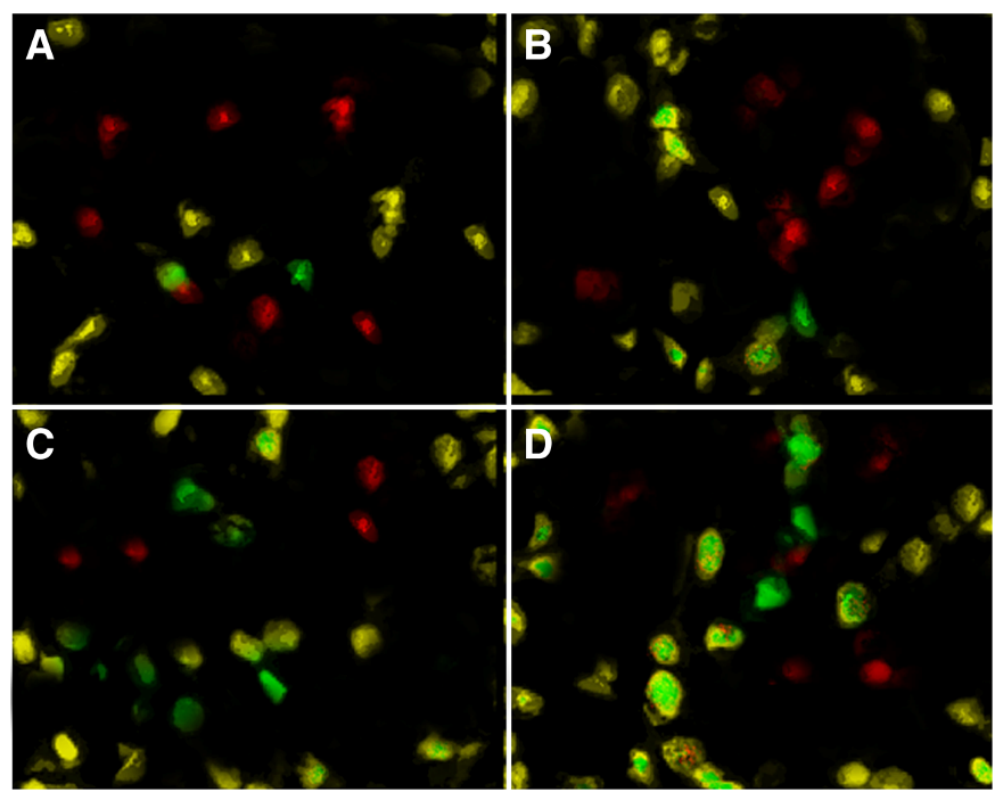

Figure 7 Double Immunofluorohistochemistry With TUNEL and c-Kit in stomach tissues( $\times \mathbf{4 0 0}$ times). A: Group l=normal control rats; B. Group IV=normal + curcumin treated rats $\mathbf{C}$. Group $\| \mid=$ diabetic + curcumin treated rats. D. Group $\|=$ diabetic control rats; Representative images of TUNEL positive and c-kit positive ICC from sections of stomach tissues of diabetic rats.Red were c-kit positive cells in tissues. Green were apoptotic cells in tissues.Yellow were TUNEL positive and c-kit positive apoptotoc ICCs.Numbers of TUNEL positive and c-kit positive apoptotic ICCs(yellow stain)expressed as the \% of total number of ICCS in the circular muscle layer of each section. Yellow-stained ICCs are undergoing apoptosis.

restrained NF- $\mathrm{kB}$ activation and improved SCF/Kit expression (e.g. restored to normal levels).

Diabetes is a pathologic condition, and the morbidity and mortality associated with diabetes are the result of myriad complications related to the disease. Oxidative stress plays an important role in the etiology of the disease, and is considered to be the main factor leading to the development of diabetic complications and tissue injury [25]. Diabetes is associated with increased oxidative stress [26]. Oxidative stress mediates many of the deleterious effects of diabetes on organ function, and induces not only gastric mucosal injury, but also gastric motility dysfunction, such as diabetic gastroparesis [7]. Gastroparesis is thought to be caused by ROS-induced damage to the networks formed by ICCs [27]. Moreover,

Table 2 Apoptotic value of ICCs in stomach tissue sections in four groups

\begin{tabular}{lc}
\hline Groups & Apoptotic indexa(AI)(\%) \\
\hline Group I & $6.4 \pm 1.8^{*}$ \\
Group II & $47.5 \pm 6.2$ \\
Group III & $26.2 \pm 4.1^{\# \Delta}$ \\
Group IV & $7.1 \pm 2.4^{*}$ \\
\hline
\end{tabular}

Group I=normal control rats; Group II=diabetic control rats; Group III= diabetic +curcumin treated rats $(150 \mathrm{mg} / \mathrm{kg})$; Group IV=normal + curcumin treated rats $(150 \mathrm{mg} / \mathrm{kg}){ }^{*} P<0.001$, significant difference compared to Group II; \# $P<0.01$, significant difference Compared to Group II. $\Delta P<0.05$ significant difference compared to Group I and Group IV. antioxidants can reverse diabetic gastroparesis in NOD mice [6]. ICCs in normal tissues are resistant to oxidative stress caused, for example, by hyperglycemia [28], but they can become vulnerable to glycemic stress when antioxidant defenses are compromised [6]. The results of our study show the potential mechanisms by which oxidative stress induces gastric motility dysfunction in diabetic rats. Diabetic rats exhibited slower gastric emptying together with increased MDA levels and decreased SOD levels compared with normal rats, with a tight correlation between high levels of MDA and the presence of delayed gastric emptying. Why does oxidative stress damage stomach function? ROS might inflict direct damage to vital cell constituents such as lipids, proteins and DNA, but also modulate patterns of gene expression through functional alterations of transcription factors such as NF- $\mathrm{kB}$ [29]. First, mature ICCs are easily damaged under conditions of oxidative stress [6]. ROS are a crucial regulator of cellular signal transduction and energy transmission, and a disturbance of the balance between ROS-generating and ROS-scavenging capabilities might lead to cell damage. Oxidative stress is now recognized as a stimulator of cell responses such as apoptosis [30]. A growing number of studies have described that ROS can activate inflammasomes in cells, leading to increased production of TNF- $\alpha$, IL-1, IL- 6 and IL-18 [31]. All sorts of inflammatory factors may directly damage ICCs. We examined the effect of 
curcumin on ROS formation in stomach tissues. Our finding that ROS content was significantly greater in Group II animals than in Group III animals suggests that curcumin attenuates diabetes-induced ROS formation. Our results also revealed that curcumin is a potent inhibitor of ROS-induced apoptosis. NF-kB is known to be a key factor in up-regulating inflammatory cytokines. NF- $\kappa \mathrm{B}$ activation enhances the transcription of proinflammatory cytokines, and these cytokines in turn activate NF- $\mathrm{kB}$ [14]. A perturbation of $\mathrm{NF}-\mathrm{kB}$ distribution promoted inflammatory mediator-mediated ICC apoptosis. NF- $\kappa B$ is normally located in cytoplasm where it binds $\mathrm{I}-\mathrm{kB}$ to form an inactive complex. The phosphorylation and subsequent degradation of $\mathrm{I}-\mathrm{kB}$ result in NF$\kappa B$ activation. We found that the NF- $\kappa B$ level in the cytoplasm was higher in diabetic rats than in control rats. Activated NF-kB migrates into the nucleus, and causes the expression of inflammatory cytokines. A comparison of the nuclear NF- $\mathrm{kB}$ levels in Group II and III rats revealed that nuclear localization of NF- $\mathrm{kB}$ is markedly inhibited by curcumin. We also found that $I-\kappa B$ is degraded in the stomach smooth muscle of diabetic rats. Activation of NF- $\mathrm{kB}$ was induced by phosphorylation of the inhibitor $\mathrm{IkB}$, in response to diverse stimuli including ROS, which leads to its degradation and results in unmasking of nuclear localization signals that allow NF$\kappa \mathrm{B}$ to be translocated into the cell nucleus [32]. ROS can directly activate NF- $\mathrm{KB}$ by degrading or modifying $\mathrm{I}-\mathrm{k} B$ in the cytoplasmic NF- $\mathrm{B}-\mathrm{I} \kappa \mathrm{B}$ complex [33]. The results of this study show that, in rats with experimentally induced gastroparesis, proteolysis of IkB results in activation and nuclear translocation of NF- $\mathrm{BB}$, and that this was accompanied by ROS up-regulation. Previously, various authors have reported that curcumin is a potent inhibitor of transcription factors [34,35], and that the suppression of NF-kB activation by curcumin results, in turn, in a down-regulation of ROS and inflammation [36].

It was suggested that loss of ICCs might have a major role in the pathogenesis of diabetic gastroparesis [37], and that the degree of ICC loss was in proportion to the severity of symptoms or changes in gastric emptying. Curcumin neutralized diabetes-induced oxidative stress, reduced MDA levels, improved SOD levels, restored NF- $\mathrm{kB}$ activity, and inhibited inflammatory mediator production, thereby minimizing diabetes-induced ICC apoptosis. All of these observations point toward a crosstalk between a ROS-NF- $\mathrm{kB}$-inflammation mediator in deciding the fate of ICC cells in a high glucose micro-environment, and the intervening role of curcumin.

Reduced SCF levels in the stomachs of diabetic mice have been reported [38]. Because SCF/c-Kit signaling is important for the maintenance of ICC phenotypes, proliferation, and differentiation [25], we investigated whether ICCs could regenerate after impairment in diabetic rats following curcumin treatment. Furthermore, the kit ligand SCF was mainly observed in the smooth muscle cells (SMCs), which are located close to ICCs. In the proximal stomach, intramuscular ICC rather than myenteric ICC are the main subtypes of ICCs that give rise to gastric slow waves and act as the dominant pacemaker cells. Previous studies have shown that SCF is important for maintaining a steady level of ICCs in stomach tissues. SCF is produced by SMCs in the longterm maintenance of ICCs, while ICC depletion in diabetes is accompanied by smooth-muscle atrophy and reduced SCF levels [39]. Exogenous SCF can partially reverse the pathological changes in ICCs in diabetic mice, because SCF is necessary for differentiation of precursors into ICCs [38]. In our study, we found the SCF/ c-kit levels and ICC numbers were clearly declined in diabetic gastroparesis rats compared with control rats. Indeed, the loss of SCF might be responsible for the loss of ICCs. The levels of mRNA expression for SCF and ckit were lower in the stomach tissues of diabetic rats than non-diabetic rats, and decrease was significantly reversed by the curcumin intervention. These findings showed that curcumin improves SCF/c-kit levels in the stomach tissues of diabetic rats. These results also indicate that the fate of ICCs in diabetes depends on SCF/ckit from SMCs, but probably not that from myenteric neurons [38]. No differences in fasting blood glucose levels and body weight were noted before and after treatment in the same groups of rats, indicating that the pathologic ICCs changes can be attributed to a deficiency of endogenous SCF/c-kit, and not related to hyperglycemia. We showed that ICC loss owing to diabetes involves reduced expression of SCF/c-kit and a critical differentiation and survival factor for ICCs. Developmental studies have demonstrated that $\mathrm{c}-\mathrm{kit}^{+}$mesenchymal precursor cells appear to generate ICCs and the longitudinal muscle layer [39]. Cell fate decisions between becoming an ICC or a SMC depend on SCF/c-kit signaling. We found that a loss or lack of SCF and c-kit ligand could lead to the apoptosis of ICCs, but when Group II rats were treated with curcumin, we observed an increase in SCF/c-kit concentration in the microenvironment promoting ICC transdifferentiation back into a normal phenotype. Our results suggest that curcumin could aid in the restoration of the SCF/c-kit signaling pathway, which is essential for ICC phenotype restoration and functional recovery. These results reinforce the results of previous studies showing that ICCs displaying distinctive plasticity can be controlled by changing the level of SCF/c-kit signaling.

Overall, our results show that curcumin has an effect on anti-oxidation and free radical removal. We further show that curcumin reduces activation of $\mathrm{NF}-\mathrm{kB}$ via 
inhibition of oxidative stress. In addition, our results suggest that curcumin promotes the expression of SCF/ c-kit. As a result, we have a better understanding of the molecular mechanism by which curcumin protects ICCs, namely, via blocking of oxidative stress, inhibition of $\mathrm{NF}-\mathrm{kB}$ activation and an enhancement of SCF/c-kit expression.

\section{Conclusion}

We suggest that curcumin can have a remarkable protective effect on ICCs and a therapeutic effect on gastric emptying dysfunction in diabetic rats.

\section{Competing interests}

The authors declare that they have no competing interests.

\section{Authors' contributions}

WH, SHX and SQY carried out the experimental work, biochemical analysis, and statistical analysis, and performed interpretation and discussion of results related to their part of the work. JQH and LQ designed and planned the study, and drafted and revised the manuscript. All authors read and approved the final manuscript.

\section{Acknowledgements}

This study was funded by the Administration of Traditional Chinese Medicine of Zhejiang Province (2010ZB076) and the Department of Health of Zhejiang Province (N20100767).

\section{Author details}

'Department of Geriatric Medicine, The Second affiliated Hospital of Zhejiang University School of Medicine, Hangzhou, Zhejiang, China. ${ }^{2}$ Department of Radiotherapy, The Second affiliated Hospital of Zhejiang University School of Medicine, Hangzhou, Zhejiang, China. ${ }^{3}$ Department of Science and Education, Zhejiang Chinese Medical University, Hangzhou, Zhejiang, China. ${ }^{4}$ Department of Animal experimental center, Zhejiang Chinese Medical University, Hangzhou, Zhejiang, China.

Received: 2 August 2012 Accepted: 20 February 2013

Published: 1 March 2013

\section{References}

1. Camilleri M: Advances in diabetic gastroparesis. Rev Gastroenterol Disord 2002, 2:47-56

2. Kashyap P, Farrugia G: Diabetic Gastroparesis: what we have learned and had to unlearn in the past 5 years. Gut 2010, 59:1716-26.

3. Malagelada JR, Distrutti E: Management of gastrointestinal motility disorders: a practical guide to drug selection and appropriate ancillary measures. Drugs 1996, 52:494-506.

4. Iwasaki H, Kajimura M, Osawa S, Kanaoka S, Furuta T, Ikuma M, Hishida A A deficiency of gastric interstitial cells of Cajal accompanied by decreased expression of neuronal nitric oxide synthase and substance $P$ in patients with type 2 diabetes mellitus. J Gastroenterol 2006, 41:1076-1087.

5. Maeda H, Yamagata A, Nishikawa S, Yoshinaga K, Kobayashi S, Nishi K, Nishikawa S: Requirement of c-kit for development of intestinal pacemaker system. Development 1992, 116:369-375.

6. Choi KM, Gibbons SJ, Nguyen TV, Stoltz GJ, Lurken MS, Ordog T, Szurszewski JH, Farrugia G: Heme oxygenase-1 protects interstitial cells of Cajal from oxidative stress and reverses diabetic gastroparesis. Gastroenterology 2008, 135:2055-2064.

7. Baynes JW: Role of oxidative stress in development of complications in diabetes. Diabetes 1991, 40:405-412.

8. Yallapu MM, Jaggi M, Chauhan SC: Curcumin nanoformulations: a future nanomedicine for cancer. Drug Discov Today 2012, 17:71-80.

9. Jurenka JS: Anti-inflammatory properties of curcumin, a major constituent of curcuma longa: a review of preclinical and clinical research. Altern Med Rev 2009, 14:141-53.
10. Mrudula T, Suryanarayana P, Srinivas PN, Reddy GB: Effect of curcumin on hyperglycemia-induced vascular endothelial growth factor expression in streptozotocin-induced diabetic rat retina. Biochem Biophys Res Commun 2007, 361:528-532.

11. Tikoo K, Meena RL, Kabra DG, Gaikwad AB: Change in post-translational modifications of histone $\mathrm{H} 3$, heat-shock protein-27 and MAP kinase p38 expression by curcumin in streptozotocin-induced type I diabetic nephropathy. Br J Pharmacol 2008, 153:1225-1231.

12. Hamaguchi T, Ono K, Yamada M: REVIEW: curcumin and Alzheimer's disease. CNS Neurosci Ther 2010, 16:285-297.

13. Sreehayan, Rao MN: Nitric oxide scavenging by curcuminoids. J Pharm Pharmacol 1997, 49:105-107.

14. Chiu J, Khan ZA, Farhangkhoee H, Chakrabarti S: Curcumin prevents diabetes-associated abnormalities in the kidneys by inhibiting p300 and nuclear factor-kappaB. Nutrition 2009, 25:964-972.

15. Gilmore TD, Garbati MR: Inhibition of NF-KB signaling as a strategy in disease therapy. Curr Top Microbiol Immunol 2011, 349:245-263.

16. Patumraj S, Wongeakin N, Sridulyakul P, Jariyapongskul A, Futrakul N, Bunnag S: Combined effects of curcumin and vitamin $C$ to protect endothelial dysfunction in the iris tissue of STZ-induced diabetic rats. Clin Hemorheol Microcirc 2006, 35:481-489.

17. Matsuda H, Li Y, Yamahara J, Yoshikawa M: Inhibition of gastric emptying by triterpene saponin, momordin Ic, in mice: roles of blood glucose, capsaicin-sensitive sensory nerves, and central nervous system. J Pharmacol Exp Ther 1999, 289:729-734.

18. Suchitra AD, Dkhar SA, Shewade DG, Shashindran CH: Relative efficacy of some prokinetic drugs in morphine-induced gastrointestinal transit delay in mice. World J Gastroenterol 2003, 9:779-783.

19. Buege JA, Aust SD: Microsomal lipid peroxidation. Methods Enzymol 1978, 52:302-309.

20. Chen $W$, Jiang $C H$, Jin $X Y$, Shen $W H$, Song $B$, Li LK: Roles of stem cell factor on loss of interstitial cells of cajal in bladder of diabetic rats. Urology 2011, 78:1443. e1-1443.e6.

21. Essani NA, McGuire GM, Manning AM, Jaeschke H: Endotoxin-induced activation of the nuclear transcription factor NF-kBin hepatocytes. Kupffer cells and endothelial cells in vivo. J Immunol 1996, 156:29-56.

22. Na HJ, Lee SJ, Kang YC, Cho YL, Nam WD, Kim PK, Ha KS, Chung HT, Lee H, Kwon YG, Koh JS, Kim YM: Inhibition of farnesyltransferase prevents collagen-induced arthritis by down-regulation of inflammatory gene expression through suppression of p21(ras)-dependent NF-KB activation. J Immunol 2004, 173:1276-1283.

23. Gibbons SJ, De Giorgio R, Faussone Pellegrini MS, Garrity-Park MM, Miller SM, Schmalz PF, Young-Fadok TM, Larson DW, Dozois EJ, Camilleri M, Stanghellini V, Szurszewski JH, Farrugia G: Apoptotic cell death of human interstitial cells of cajal. Neurogastroenterol Motil 2009, 21:85-93.

24. Flohe AL, Brigelius-Flohe AR, Saliou C, Traber MG, Packer L: Redox regulation of NF-kB activation. Free Radic Biol Med 1997, 22:1115-1126.

25. Giacco F, Brownlee M: Oxidative stress and diabetic complications. Circ Res 2010, 107:1058-70.

26. Varvarovská J, Racek J, Stetina R, Sýkora J, Pomahacová R, Rusavý Z, Lacigová S, Trefil L, Siala K, Stozický F: Aspects of oxidative stress in children with type 1 diabetes mellitus. Biomed Pharmacother 2004, 58:539-545.

27. Forster J, Damjanov I, Lin ZY, Sarosiek I, Wetzel P, McCallum RW: Absence of the interstitial cells of Cajal in patients with gastroparesis and correlation with clinical findings. Gastroenterology 2003, 124:A788-A789.

28. Horvath VJ, Vittal H, Ordog T: Reduced insulin and IGF-I signaling, not hyperglycemia, underlies the diabetes-associated depletion of interstitial cells of Cajal in the murine stomach. Diabetes 2005, 54:1528-1533.

29. Van den Berg R, Haenen GR, Van den Berg H, Bast A: Transcription factor NF$\mathrm{kB}$ as a potential biomarker for oxidative stress. Br J Nutr 2001, 86:S121-S127.

30. Thomas MB, Paul AS: Oxidative stress as a mediator of apoptosis. Immunol Today 1994, 15:7-10.

31. Trachootham D, Alexandre J, Huang P: Targeting cancer cells by ROSmediated mechanisms: a radical therapeutic approach? Nat Rev Drug Discov 2009, 8:579-591.

32. Verma IM, Stevenson J: IkappaB kinase: beginning, not the end. Proc Natl Acad Sci USA 1997, 94:11758-11760.

33. Liu TZ, Hu CC, Andrew C, Chen Y, Stern A, Cheng JT: Differentiation status modulates transcription factor NF-kB activity in unstimulated human hepatocellular carcinoma cell lines. Cancer Letts 2000, 151:49-56. 
34. Foryst-Ludwig A, Neumann M, Schneider-Brachert W, Naumann M: Curcumin blocks NF-kappaB and the motogenic response in helicobacter pylori-infected epithelial cells. Biochem Biophys Res Commun 2004, 316:1065-1072.

35. Zhong Y, Liu T, Guo Z: Curcumin inhibits ox-LDL-induced MCP-1 expression by suppressing the p38MAPK and NF-KB pathways in rat vascular smooth muscle cells. Inflamm Res 2012, 61:61-67.

36. Woo JM, Shin DY, Lee SJ, Joe Y, Zheng M, Yim JH, Callaway Z, Chung HT: Curcumin protects retinal pigment epithelial cells against oxidative stress via induction of heme oxygenase-1 expression and reduction of reactive oxygen. Mol Vis 2012, 18:901-908.

37. Ordög T, Takayama I, Cheung WK, Ward SM, Sanders KM: Remodeling of networks of interstitial cells of Cajal in a murine model of diabetic gastroparesis. Diabetes 2000, 49:1731-1739.

38. Horvath VJ, Vittal H, Lorincz A, Chen H, Almeida-Porada G, Redelman D, Ordog T: Reduced stem cell factor links smooth myopathy and loss of interstitial cells of cajal in murine diabetic gastroparesis. Gastroenterology 2006, 130:759-770.

39. Kluppel M, Huizinga JD, Malysz J, Bernstein A: Developmental origin and Kit-dependent development of the interstitial cells of cajal in the mammalian small intestine. Dev Dyn 1998, 211:60-71.

doi:10.1186/1758-5996-5-12

Cite this article as: Jin et al:: Curcumin improves expression of SCF/c-kit through attenuating oxidative stress and NF-KB activation in gastric tissues of diabetic gastroparesis rats. Diabetology \& Metabolic Syndrome 2013 5:12.

\section{Submit your next manuscript to BioMed Central and take full advantage of:}

- Convenient online submission

- Thorough peer review

- No space constraints or color figure charges

- Immediate publication on acceptance

- Inclusion in PubMed, CAS, Scopus and Google Scholar

- Research which is freely available for redistribution 